\title{
Associations between routinely collected Dairy Herd Improvement data and insemination outcome in UK dairy herds
}

\author{
C. D. Hudson ${ }^{1}$ and M. J. Green \\ School of Veterinary Medicine and Science, University of Nottingham, Sutton Bonington, LE12 5RD, United Kingdom
}

\begin{abstract}
Milk constituent concentrations in samples taken during early lactation are often used to generate proxy measures for energy balance in dairy herds. This study aimed to explore associations between these and other measures routinely recorded by Dairy Herd Improvement schemes and insemination outcome, with an emphasis on the likely predictiveness of such measures for conception risk (the proportion of inseminations that are successful) at herd level. Data from 312 UK dairy herds were restructured so that each unit of data represented an insemination at less than $100 \mathrm{~d}$ in milk (DIM). Milk constituent concentrations from the first and second test days (corrected for the effects of season and DIM at sampling) were used as potential predictors of insemination outcome in a logistic regression model. Other predictors included representations of milk yield and other information routinely collected by Dairy Herd Improvement Associations; random effects were used to account for clustering at cow and herd levels. The final model included a large number of predictors, with several interaction and nonlinear terms. The relative effect sizes of the measures of early lactation milk constituent concentrations were small. The full model predicted just under $64 \%$ of observed variation in herdyear conception risk (i.e., the proportion of inseminations that were successful in each herd in each calendar year); however, around $40 \%$ was accounted for by the herd-level random effect. The predictors based on early lactation milk constituent concentrations accounted for less than $0.5 \%$ of observed variation, and representations of milk yield (both overall level of yield and early lactation curve shape) accounted for around 7\%; DIM at insemination, parity, interservice interval, year, and month accounted for the remaining $15 \%$. These results suggest that early lactation milk constituent informa-
\end{abstract}

Received October 9, 2017.

Accepted August 3, 2018.

${ }^{1}$ Corresponding author: chris.hudson@nottingham.ac.uk tion is unlikely to predict herd conception risk to a useful extent. The large proportion of observed variation explained by the herd-level random effect suggests that there are unmeasured (in this study) or unmeasurable factors that are consistent within a herd and are highly influential in determining herd conception risk.

Key words: fertility, conception risk, dairy cow, Dairy Herd Improvement data

\section{INTRODUCTION}

It is widely recognized that improving reproductive performance has great scope to improve the profitability of an individual dairy unit and has a role in securing the economic and environmental sustainability of the industry as a whole (Archer et al., 2015). Broadly, a herd's overall level of reproductive performance is determined by 2 factors. The first is the proportion of eligible cows coming into estrus and being inseminated per unit time (commonly termed submission rate; dependent on cow cyclicity and, in herds using AI, also dependent on estrus detection or cycle manipulation). The second is the proportion of inseminations that lead to a pregnancy, variously known as pregnancy rate, conception rate, and conception risk (CR). In the United Kingdom, as in many other dairying nations, the medium-term trend has been a decline in overall reproductive performance (Norman et al., 2009; Hudson et al., 2010; Morton, 2011). Efforts to mitigate or reverse this decline have mostly focused on improving submission rate, as this tends to be much more amenable to manipulation, and for most herds there is substantial scope for improvement. There is some evidence that these strategies have been at least partially successful (Hanks and Kossaibati, 2016), and as submission rates increase the relative importance of CR becomes greater.

A wide range of factors associated with the outcome of an insemination have been described. One of the most widely explored and likely most important is early lactation energy balance. A period of negative energy balance (defined as daily energy output in excess of energy intake) is considered to be normal in modern 
early lactation dairy cows (Jorritsma et al., 2003), but the severity and duration of negative energy balance has been shown to affect CR during early lactation via several physiological pathways (Villa-Godoy et al., 1988; Butler, 2001; Wathes et al., 2007; Leroy et al., 2008a). Monitoring early lactation energy balance is therefore likely to be important in maximizing a herd's $\mathrm{CR}$, as it will allow problems to be identified early and strategies to improve energy balance to be put in place. Several monitoring approaches exist, with body condition scoring and evaluation of blood metabolite (e.g., BHB and nonesterified fatty acid) concentrations being among the most popular. However, these require time and incur cost, so alternative monitoring approaches are attractive.

Milk constituent concentrations (from routinely collected DHI and milk recording samples) in early lactation have been used as proxy measures of energy balance (Coulon and Rémond, 1991; de Vries and Veerkamp, 2000), with the ratio of butterfat to protein concentration (fat:protein ratio) being the most widely reported. Although fat:protein ratio has been associated with reduced fertility (Heuer et al., 1999; Loeffler et al., 1999; Podpečan et al., 2008) and increased risk of early lactation disease (Geishauser et al., 1998; Heuer et al., 1999), there is little evidence to suggest that it is a useful direct predictor of energy balance (Duffield et al., 1997). A study using a large data set derived from UK herds (Madouasse et al., 2010) found that a model including several measures of early lactation milk constituent concentration and yield was predictive of calving to conception interval but that fat:protein ratio at either the first or second test day of lactation had no significant association with this outcome when the other predictor variables were included. The objective of this study was to explore associations between the information routinely recorded as part of DHI or milk recording schemes and the outcome of early lactation inseminations, with an emphasis on the potential predictiveness of such measures for CR at herd level.

\section{MATERIALS AND METHODS}

\section{Data Collection and Restructuring}

A convenience sample of routinely recorded management data was collected from 312 dairy herds across England and Wales; data collection and initial audit were previously described in Hudson et al. (2012). Data from lactations beginning between 1999 and 2008 were used, and lactations were included only where a milk recording test day occurred within both intervals 5 to 35 DIM and 36 to 65 DIM. These intervals were consid- ered to represent typical first and second test days of a lactation. Where there was more than 1 recording event within an interval, the recording nearest to the center of the interval was selected. At each test day, daily milk yield and concentrations of protein, butterfat, and lactose were recorded. To account for the possibility that milk constituent concentrations and yields would be affected by DIM at time of sampling (such that a daily yield of $45 \mathrm{~L}$ at a first test day at 10 DIM was treated differently than the same yield at a first test day at 30 DIM) and day of the year, milk recording data were standardized using the approach described in Madouasse et al. (2010). Briefly, continuous-outcome linear regression models were constructed using the complete data set, taking each milk recording variable in turn as the outcome. Polynomial terms (order $\leq 6$ ) representing DIM and trigonometric functions representing day of the year at time of sampling were used as predictor variables, and models were built using forward selection. These models were then used to estimate an expected value for each variable at each milk recording event in the data set (given the DIM and day of year of that recording). The expected values for each lactation were then used to standardize the observed values by subtracting expected from observed and dividing by standard deviation, such that the standardized values for each variable had mean 0 and standard deviation 1 across the data set. To illustrate the changes in these variables associated with DIM and stage of year at time of sampling, these models were used to generate predictions across the range of DIM (5-65) and day of year (1-365) and the predictions were represented as 3-dimensional surface plots.

The data set was then restructured such that each unit of data represented an insemination at up to 100 DIM, with a total of 134,520 inseminations from 77,803 cows in 312 herds. Potential explanatory variables at lactation level (including those related to first and second milk recording test days) were replicated and aligned with each insemination from the same lactation. Additional insemination level variables were also included; a binary variable was used to represent the outcome of the insemination. Inseminations were eligible for inclusion if they were from parities that ended in either a subsequent calving date or an exit date and where herd calving and exit records were available for at least 1 yr after insemination date. Herd-years were excluded if they failed to meet data quality criteria or recorded fewer than 50 inseminations. Inseminations were classified as successful either if they were followed by a calving event 266 to 296 d later (McGuirk et al., 1998, 1999) or if the animal exited the herd following a positive pregnancy diagnosis. Pregnancy diagnosis 
Table 1. Potential explanatory variables at each level of data used to build a logistic regression model with the outcome of insemination success or failure

\begin{tabular}{|c|c|c|c|}
\hline Variable & Representation & \multicolumn{2}{|c|}{ Distributional characteristics } \\
\hline Outcome & Binary & Mean $=0.4$ & $0.42(0.17-0.70)$ \\
\hline DIM at insemination & Polynomial (order <4) & Mean $=72 \mathrm{~d}, \mathrm{SD}=17 \mathrm{~d}$ & $73(63-87)$ \\
\hline Month of insemination & $\begin{array}{l}\text { Categorical; months as individual } \\
\text { categories }\end{array}$ & & \\
\hline \multicolumn{4}{|l|}{ Lactation level } \\
\hline 305-d lactation yield & $\begin{array}{l}\text { Centered around population mean, } \\
\text { polynomial }(\text { order }<4 \text { ) }\end{array}$ & $\begin{array}{l}\text { Mean }=8,230 \mathrm{~L}, \mathrm{SD}= \\
2,167 \mathrm{~L}\end{array}$ & $8,067(4,944-10,433)$ \\
\hline Month of calving & $\begin{array}{l}\text { Categorical; months as individual } \\
\text { categories }\end{array}$ & & \\
\hline Lactation number & Categorical $(1,2,3,4,5+)$ & $0.26,0.23,0.18,0.12,0.20$ & $\begin{array}{l}\text { Lactation 1: } 0.25(0.00- \\
0.54) \\
\text { Lactation } 5+: 0.20(0.00- \\
0.46)\end{array}$ \\
\hline Butterfat $\%$ at recording 2 & \multirow{9}{*}{\multicolumn{2}{|c|}{$\begin{array}{l}\text { Linear, standardized for DIM and day of year at recording such that } 0 \\
\text { represents expected population mean given DIM and day of year, and a } 1 \\
\text { unit change represents } 1 \text { population SD }\end{array}$}} & $-0.05(-0.79$ to 1.12$)$ \\
\hline Protein $\%$ at recording 1 & & & $0.01(-0.65$ to 1.21$)$ \\
\hline Protein $\%$ at recording 2 & & & $-0.02(-0.79$ to 1.35$)$ \\
\hline Lactose $\%$ at recording 1 & & & $0.00(-0.71$ to 0.98$)$ \\
\hline Lactose $\%$ at recording 2 & & & $-0.02(-0.78$ to 0.98$)$ \\
\hline Fat:protein ratio at recording 1 & & & $-0.05(-0.82$ to 0.87$)$ \\
\hline Fat:protein ratio at recording 2 & & & $-0.04(-0.88$ to 0.94$)$ \\
\hline Daily yield at recording 1 & & & $-0.04(-1.48$ to 0.95$)$ \\
\hline Daily yield at recording 2 & & & $-0.04(-1.58$ to 0.98$)$ \\
\hline
\end{tabular}

${ }^{1}$ Distributional characteristics across inseminations in the data set; means and SD are reported for continuous variables, and proportion in each category (reported in the order the categories are listed in the "Representation" column) is reported for categorical variables.

${ }^{2}$ Herd-year level distributional characteristics are median and $95 \%$ coverage interval for the means of each continuous variable for each herd-year (i.e., the first value represents the median herd-years, and the numbers in parentheses represents the range covering $95 \%$ of herd-years). For categorical variables, the variation in proportion of the herd in certain categories is reported in the same way.

${ }^{3}$ Indicates the first insemination of a lactation.

results were not used where a subsequent calving event was recorded. Where multiple inseminations occurred 266 to $296 \mathrm{~d}$ before a calving event, the insemination giving a gestation period closest to $282 \mathrm{~d}$ was classified as successful and the others were classified as unsuccessful. Where a positive pregnancy diagnosis was followed by an exit from the herd, the last recorded insemination was considered to be successful unless the pregnancy diagnosis event specifically recorded pregnancy to an earlier insemination. The potential predictor variables used in model building are shown in Table 1. Data restructuring and standardization were carried out using $\mathrm{R}$ version 3.0.0 (R Core Development Team, 2010).

Interservice interval (number of days since previous insemination) was included as a potential explanatory variable because it was plausible that it could influence CR (e.g., CR may be lower where the interval from the previous insemination is very short, potentially representing insemination outside of an estrus event). To explore the potential importance of the choice of interservice interval categories (reflecting the possibility that 18-24 d does not represent an appropriate choice of "normal" range; Remnant et al., 2015; Blavy et al., 2016), model building was repeated using categories based on a 19- to 26-d "normal." This comparison of category choices (normal of 18-24 d vs. 19-26 d) was repeated using a data set comprising inseminations up to 200 DIM (compare with 100 DIM for the main analysis described).

\section{Model Construction}

A multilevel logistic regression model was built to explore associations between the outcome (establishment of pregnancy following insemination) and the potential predictors. A 3-level structure was used to account for the hierarchically clustered structure of the data (with inseminations nested within cow, which were nested within herds). A 4-level structure (with lactations as the additional level) was rejected owing to the large number of cows contributing inseminations from a single lactation. The model took the form 


$$
\begin{gathered}
\operatorname{Preg}_{i j k l} \sim \operatorname{Bernoulli}\left(\operatorname{mean}=\mu_{i j k l}\right) \\
\ln \left(\frac{\mu_{i j k l}}{1-\mu_{i j k l}}\right)=\alpha+\boldsymbol{\beta}_{1} \mathbf{X}_{i j k l}+\boldsymbol{\beta}_{2} \mathbf{X}_{j k l}+\mathrm{u}_{k l}+\mathrm{v}_{l} \\
\mathrm{v}_{l} \sim \text { normal distribution }\left(0, \sigma_{v}^{2}\right) \\
\mathrm{u}_{k l} \sim \text { normal distribution }\left(0, \sigma_{u}^{2}\right),
\end{gathered}
$$

where $i$ represents a given insemination from lactation $j$ of cow $k$ in herd $l ; \mu_{i j k l}$ is the fitted probability of Preg $_{i j k l}$ (the outcome insemination $i$ leading to a pregnancy); $\alpha$ is the regression intercept; $\boldsymbol{\beta}_{1}$ is the vector of coefficients corresponding to the vector of inseminationlevel predictors $\mathbf{X}_{i j k l} ; \boldsymbol{\beta}_{2}$ is the vector of coefficients corresponding to the vector of lactation-level predictors $\mathbf{X}_{j k l} ; \mathrm{u}_{k l}$ is the random effect to reflect variation between individual cows; and $\mathrm{v}_{l}$ is the random effect representing variation between herds, with $\sigma_{u}^{2}$ and $\sigma_{v}^{2}$ being the variances of the normal distributions of the random effects terms representing cow and herd, respectively.

Model building was carried out by forward selection, with terms retained in the model if the magnitude of the estimated coefficient was greater than double the standard error of the estimate. Univariable associations between the proportion of successful inseminations and each predictor variable in turn were evaluated, and where this suggested a nonlinear pattern a polynomial representation of that predictor variable was tested in the model. Categorical variables where several categories had similar parameter estimates were recoded by combining categories for model parsimony. All possible first-order interactions were tested in the model and retained where they met the criteria described above or altered the estimate for at least 1 other parameter by at least $10 \%$. For terms relating to early lactation milk records, interactions with the natural logarithm of DIM at insemination were tested to allow for the possibility that these have decreasing strength of association with inseminations further into lactation. All rejected predictor variables were retested in the final model and retained if they met the criteria above. Model building was carried out in MLwiN version 2.29 (Rasbash et al., 2010), with iterative generalized least squares used for exploratory model building, and Markov chain Monte Carlo (MCMC) with diffuse prior distributions used over 20,000 iterations for final parameter estimation (Browne, 2009). Visual assessment of MCMC chain behavior was carried out to ensure that satisfactory convergence had occurred.

To evaluate model fit, full posterior predictions were generated for each insemination using the full MCMC chain for each parameter. The data set was subset in a variety of ways, including subsets based on variables included in the model (e.g., subset by parity) and subsets based on other variables (e.g., subset by month of calving). Model fit was considered acceptable where the observed CR across a subset of inseminations fell within the $95 \%$ coverage interval of the predicted posterior distribution for that subset. The MCMC chains were exported to $\mathrm{R}$ version 3.0 .0 for generation and analysis of model predictions.

\section{Illustration of Results Using Posterior Predictions}

Posterior predictions were also used for out-of-sample predictions to demonstrate how the probability of a successful insemination would be expected to vary if one predictor was varied over a given range and the others were held at their population means. For each milk recording variable, the range chosen was -2 to 2 ; as these variables were standardized, this represented $2 \mathrm{SD}$ on either side of the population mean. Line plots were used to represent each relationship. The same approach was used to illustrate interactions between predictor variables.

To evaluate the proportion of variation in a herd's CR explained by each element of the model, the data were subset into herd-years such that each subset contained all the inseminations for 1 herd in 1 calendar year; herd-years containing less than 50 inseminations were excluded. Different elements of the model (e.g., full fixed and random effects, fixed effects only, fixed effects for restricted groups of predictors) were used to generate a predicted CR for each herd-year, which was compared with the observed CR in that herd year, with the overall relationship presented using scatterplots and Pearson correlation coefficients. Comparison of coefficient of determination $\left(\mathbf{R}^{2}\right)$ values for correlations between each set of predicted herd-year CR and the corresponding observed values allowed estimation of the proportion of variation in a herd's CR explained by the different model components.

\section{Cross-Validation}

To evaluate potential predictiveness of the model on new data, cross-validation was performed. This involved subsetting the data randomly (stratified for insemination outcome and herd) into a training data set containing $80 \%$ of the inseminations and a testing data set containing the remainder. The training data set was then used to estimate model parameters (using the same random effects structure as described above, but using least squares estimation rather than MCMC for computational reasons), which were then used to 
derive predictions for the inseminations in the test data set. This process was repeated 10 times with a different stratified random split of data into training and testing sets each time, resulting in a set of predictions twice as big as the original data set. These predictions were then summarized as mean $\mathrm{CR}$ in each herd-year (excluding those with less than 50 inseminations), which were compared with the observed CR in each herd-year as described for the main model.

\section{RESULTS}

A total of 190,324 inseminations at up to 100 DIM were retrieved from herd-years meeting the data quality criteria. Of these, 12,655 were excluded as no outcome was determined by the rules described in the Materials and Methods; a further 43,149 were excluded due to other lactation-level data quality issues (most commonly missing test day milk recording information). A data set containing 134,520 inseminations was therefore used for the final analysis, of which 53,909 (40\%) were determined to have led to pregnancy (by subsequent calving in approximately $96 \%$ of successful inseminations; in approximately $4 \%$ the outcome was determined by a positive pregnancy diagnosis before culling).

Regression planes illustrating the relationship between early lactation milk recording parameters and DIM and day of year at sampling are shown in Figure 1. Interactive versions of these plots are available online (https://plot.ly/ cdhudsonx/73/, https://plot .ly/ cdhudsonx/76/, https://plot.ly/ cdhudsonx/79/, https://plot.ly/ cdhudsonx/67/, https://plot.ly/ $\sim$ cdhudsonx/82/, https://plot.ly/ cdhudsonx/85/). The concentrations of butterfat, protein, and lactose all decreased markedly, whereas milk yield increased over the first 30 DIM. Fat:protein ratio also increased through early lactation, showing a peak that was earlier and more pronounced than the nadir demonstrated by butterfat or protein concentration. Daily milk yields showed a seasonal trend, increasing through winter to a peak in spring followed by a decline through the summer months. Milk constituent concentrations tended to show a converse trend (decreasing as daily yield increased), with butterfat percentage also decreasing sharply in spring.

Parameter estimates for the logistic regression model are shown in Table 2. Of the potential predictors (see Table 1) based on milk constituent concentrations standardized for DIM and day of year at sampling, butterfat, protein, and lactose percentages at first test day and protein and lactose percentages at second test day were significantly associated with the probability of pregnancy to an insemination (CR). Of these, lactose concentration at both test days and protein concen- tration at second test day had significant interaction terms with DIM at insemination (broadly such that the effect of each was greater on inseminations earlier in lactation). These relationships are illustrated using model predictions in Figure 2. It is worth noting that these graphs illustrate the direct components of each relationship only, as they show the relationship between the outcome and 1 predictor variable after accounting for the effects of all the other predictor variables in the model. For example, if the same factors influence the concentration of lactose at both first and second test day in the same direction, the observed relationship between lactose at first test day and the outcome would be expected to appear stronger if lactose at second test day was not accounted for.

Associations between milk yield-related predictors and the outcome are illustrated using predictions in Figure 3. There was a different relationship between 305-d lactation yield and CR for first-lactation animals and mature cows; however, in each category predicted CR increased to a peak around $6,000 \mathrm{~L}$ and then declined with increasing yield beyond this. For firstlactation animals, the size of the relationship was larger and the peak CR occurred at a slightly lower yield. Test day yield at both first and second test day was also significantly associated with $\mathrm{CR}$, and there was a significant interaction between the 2 test day yield terms. For a given level of lactation yield, predicted CR was generally higher where yields at first and second test day were higher (i.e., where yield increased more quickly after calving). This relationship was relatively simple where corrected first test day yield was greater than zero (i.e., yield at first test day was greater than predicted for a test day at that DIM and day of year) but became more complex below zero. This relationship is illustrated using a predicted regression plane in Figure 4 , and an interactive version is available at https:// goo.gl/F35QR9. The associations between CR and the yield-based predictors were generally much larger than those with the constituent-based predictors.

Inseminations during the summer months and in later years were associated with lower $\mathrm{CR}$, and CR increased with DIM, although the gradient of this increase became smaller at around 70 DIM. Predicted CR was lowest for parity 1 and highest for parity 2; parities 3 and 4 were similar to parity 2 . To explore this association further, predictors were removed from the model sequentially and parameters were re-estimated. The decrease in predicted $\mathrm{CR}$ in parities above 1 was observed where the terms relating to 305-d adjusted lactation milk yield were retained in the model; where these terms were removed the association changed such that increasing parity was associated with decreasing CR. 

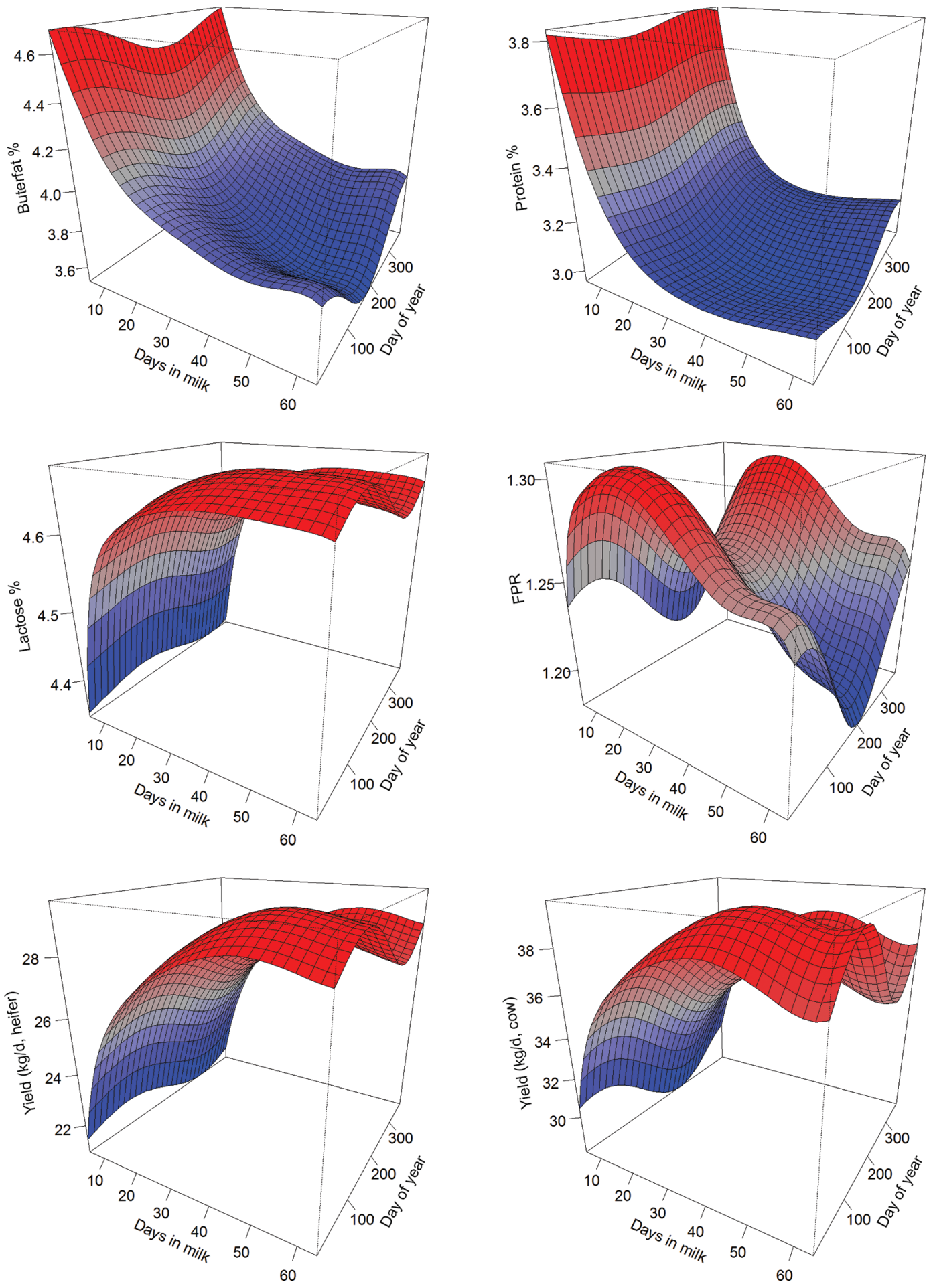

Figure 1. Regression surfaces illustrating relationship between test day milk parameters and DIM and season at sampling. FPR $=$ fat-toprotein ratio. Color version available online.

Inseminations at an interval of 18 to $24 \mathrm{~d}$ after a previous insemination had a very slightly higher CR than first inseminations; other categories of interservice interval (ISI) were associated with lower CR. Odds of a successful insemination were lowest for ISI less than $18 \mathrm{~d}$, at around $50 \%$ lower than for a first insemination. Adoption of ISI categories based on a 19- to 26-d "normal" interval made very little difference to model 
Table 2. Parameter estimates from a multivariable logistic regression model with the outcome representing pregnancy resulting from a given insemination

\begin{tabular}{|c|c|c|c|}
\hline \multirow[b]{2}{*}{ Model term } & \multirow[b]{2}{*}{ Odds ratio } & \multicolumn{2}{|c|}{$95 \% \mathrm{HPD}^{1}$ interval } \\
\hline & & Lower & Upper \\
\hline Butterfat $\%$ at recording $1^{2}$ & 0.98 & 0.97 & 1.00 \\
\hline Protein $\%$ at recording 1 & 1.05 & 1.03 & 1.06 \\
\hline Protein $\%$ at recording 2 & 1.44 & 1.21 & 1.75 \\
\hline Lactose $\%$ at recording 1 & 1.59 & 1.26 & 1.97 \\
\hline Lactose $\%$ at recording 2 & 0.72 & 0.59 & 0.89 \\
\hline$($ Protein $\%$ at recording 2$) \cdot(\operatorname{lnDIM})^{3}$ & 0.92 & 0.88 & 0.96 \\
\hline (Lactose $\%$ at recording 1$) \cdot(\operatorname{lnDIM})$ & 0.91 & 0.86 & 0.96 \\
\hline$($ Lactose $\%$ at recording 2$) \cdot(\operatorname{lnDIM})$ & 1.08 & 1.03 & 1.14 \\
\hline Daily milk yield at recording 1 & 1.16 & 1.14 & 1.19 \\
\hline Daily milk yield at recording 2 & 1.25 & 1.22 & 1.28 \\
\hline$(\text { Yield at recording } 2)^{2}$ & 1.03 & 1.02 & 1.04 \\
\hline (Yield at recording 1$) \cdot($ Yield at recording 2 ) & 1.04 & 1.03 & 1.06 \\
\hline (Yield at recording 1$) \cdot\left[(\text { Yield at recording } 2)^{2}\right]$ & 0.97 & 0.97 & 0.98 \\
\hline 305-d lactation yield $(\times 1,000 \mathrm{~L})$ & 0.75 & 0.74 & 0.76 \\
\hline$(305-d \text { lactation yield })^{2}$ & 0.96 & 0.96 & 0.96 \\
\hline$(305-d \text { lactation yield })^{3}$ & 1.01 & 1.00 & 1.01 \\
\hline$\left(305-d\right.$ lactation yield) $\cdot(\text { Parity } 1)^{4}$ & 0.86 & 0.84 & 0.88 \\
\hline$(305-d \text { lactation yield })^{2} \cdot(\text { Parity } 1)^{4}$ & 1.03 & 1.03 & 1.04 \\
\hline$(305-d \text { lactation yield })^{3} \cdot(\text { Parity } 1)^{4}$ & 1.00 & 1.00 & 1.01 \\
\hline DIM $^{5}$ & 1.12 & 1.12 & 1.13 \\
\hline$(\mathrm{DIM})^{2}$ & 1.00 & 1.00 & 1.00 \\
\hline$(\mathrm{DIM})^{3}$ & 1.00 & 1.00 & 1.00 \\
\hline Parity 1 & Referent & & \\
\hline Parity 2 & 1.54 & 1.48 & 1.61 \\
\hline Parity 3 & 1.52 & 1.46 & 1.59 \\
\hline Parity 4 & 1.40 & 1.34 & 1.47 \\
\hline Parity $>4$ & 1.15 & 1.10 & 1.20 \\
\hline ISI $^{6}$ NA (first insemination) & Referent & & \\
\hline ISI $<18 \mathrm{~d}$ & 0.49 & 0.45 & 0.53 \\
\hline ISI $18-24 \mathrm{~d}$ & 1.05 & 1.01 & 1.08 \\
\hline ISI $25-35 \mathrm{~d}$ & 0.81 & 0.76 & 0.86 \\
\hline ISI $36-48 \mathrm{~d}$ & 0.90 & 0.84 & 0.97 \\
\hline ISI $>48 \mathrm{~d}$ & 0.75 & 0.65 & 0.87 \\
\hline Summer (June-September) & 0.84 & 0.82 & 0.86 \\
\hline Year $<2003$ & Referent & & \\
\hline Year 2003 & 0.98 & 0.93 & 1.02 \\
\hline Year 2004 & 0.93 & 0.89 & 0.97 \\
\hline Year 2005 & 0.87 & 0.83 & 0.91 \\
\hline Year 2006 & 0.82 & 0.78 & 0.86 \\
\hline Year 2007 & 0.80 & 0.77 & 0.84 \\
\hline Year 2008 & 0.78 & 0.73 & 0.84 \\
\hline
\end{tabular}

${ }^{1}$ Highest posterior density.

${ }^{2}$ Butterfat, protein, lactose, and yield values are standardized to account for DIM and day of year at sampling such that a value of 0 would represent expected population mean (given DIM and day of year at sampling), with a unit change representing 1 population SD away from mean. Odds ratios are for a 1-unit change in each variable, adjusted for all other terms in the model.

${ }^{3} \operatorname{lnDIM}=$ natural logarithm of DIM at insemination.

${ }^{4}$ The relationship between 305-d yield and conception risk was very similar for all parity categories except parity 1 , so for model parsimony, only the interaction with this parity group was included.

${ }^{5} \mathrm{DIM}=\mathrm{DIM}$ at insemination.

${ }^{6} \mathrm{ISI}=$ interservice interval (days since previous insemination).

fit as measured by deviance information criterion (Spiegelhalter et al., 2002), although when analysis was repeated with a data set containing inseminations up to 200 DIM, use of the alternative ISI categories did improve model fit.

Figure 5 illustrates the use of model predictions to partition observed variation between herd-year subsets (i.e., the subset of inseminations from each herd in each year) of the data. Predictions based on the full model, including herd- and cow-level random effects, accounted for around $64 \%$ of the variation in observed herdyear CR; removing the cow-level random effect made negligible difference, whereas removing the herd-level random effect reduced the $\mathrm{R}^{2}$ value to around $22 \%$. A fixed-effect model without any milk constituent predictors accounted for a very similar proportion of varia- 

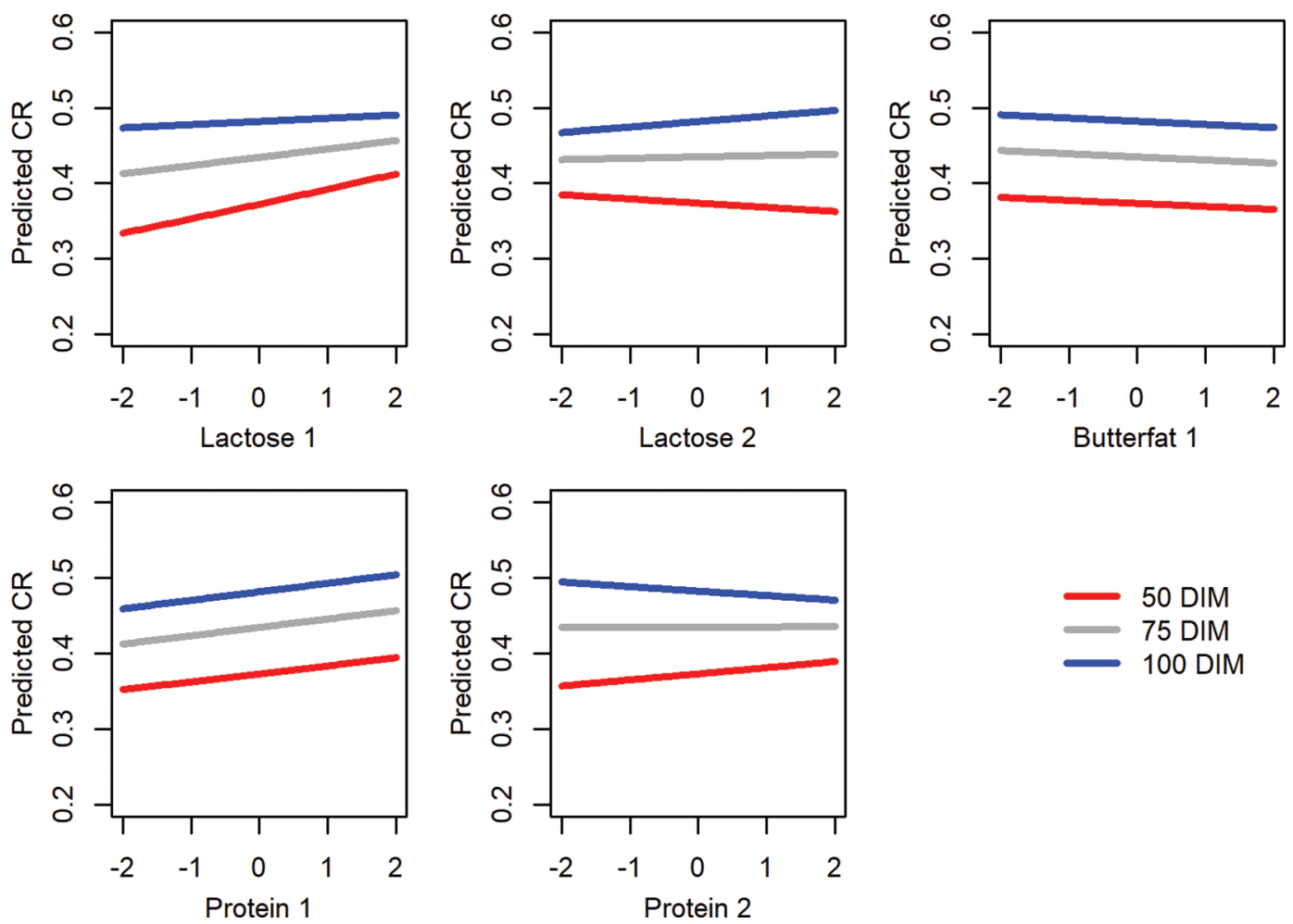

Figure 2. Predictions (from the model reported in Table 2) for example scenarios to illustrate relationships between conception risk (CR) and early lactation milk constituent concentrations. Each plot shows probability of pregnancy resulting from a set of example inseminations where all predictor values are set at their population means except for the variable indicated in the x-axis of the plot and DIM. Each line shows the variation in predicted $\mathrm{CR}$ across the range of the variable, with line colors and types representing inseminations at different stages of lactation. Milk constituent variables are standardized such that 0 represents population mean and 1 represents mean plus 1 SD compared with expected value given season and DIM at test day, and numeric suffixes represent test day number. Color version available online.

tion (just below $22 \%$ ), and removal of milk constituent and yield predictors reduced this to $15 \%$, representing the proportion of observed variation in herd-year CR explained by days in milk, parity, ISI, and year and month of insemination.

These changes in $\mathrm{R}^{2}$ value were used to partition variance in herd-year $\mathrm{CR}$ across the fixed and random effects in the model; this is shown in Figure $5 \mathrm{f}$. When predictions generated using 10-fold cross-validation were used, the fixed-effect model explained around 19\% of the observed variation in herd-year CR. This is similar to the value derived using the full data set both to estimate model parameters and to generate predictions (22\%), suggesting that the model would be similarly predictive if applied to new data from the same population.

The $95 \%$ coverage interval of model posterior predictions for a wide selection of different subsets of the data included the observed result for each subset, confirming that the model fitted the data well. Visual assessment of MCMC chain behavior revealed a small number of chains among the milk constituent concentration predictors where convergence had not clearly been achieved.
Parameters were re-estimated using a larger number of iterations (100,000 compared with 20,000 initially); this resulted in very similar parameter estimates, although in some cases chains had again not clearly converged. Recoding the problematic variables from continuous values into 5 categories each and removing their interaction terms with DIM resulted in a model with good chain behavior. Again, parameter estimates were very similar to the original model, and deviance information criterion was higher. This suggested that the model could be reparamaterized to improve MCMC chain behavior and that this resulted in a model that gave very similar information but had a poorer fit to the data. The model using continuous milk constituent predictors was therefore reported.

\section{DISCUSSION}

The main objective of this study was to investigate the relationship between routinely recorded dairy herd management information and insemination outcomes at up to 100 DIM. One aspect of interest was the association between $\mathrm{CR}$ and early lactation milk con- 

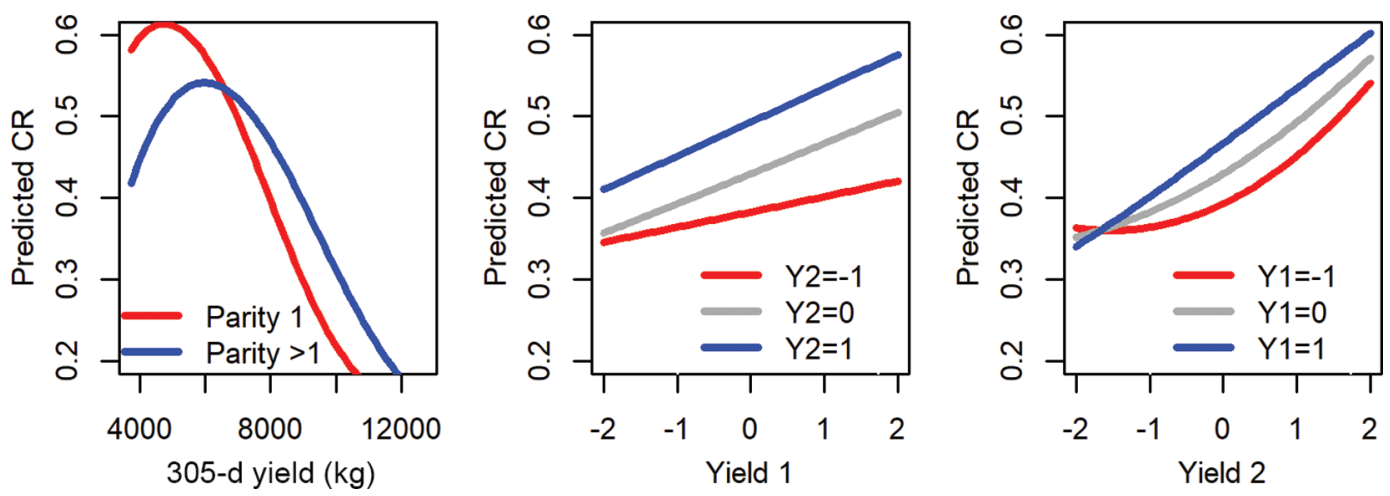

Figure 3. Predictions (from the model reported in Table 2) for example scenarios to illustrate relationships between conception risk (CR) and milk yield. Each plot shows probability of pregnancy resulting from a set of example inseminations where all predictor values are set at their population means except for the variables indicated in the plot legend and x-axis. The left plot shows predicted CR across a range of 305-d lactation yields (with line color representing parity). The central and right plots show the association between CR and daily yield at first and second test day standardized such that 0 represents population mean and 1 represents mean plus 1 SD compared with expected value given season and DIM at test day. Numeric suffixes represent test day number. Y1 = yield at first test day; Y2 = yield at second test day. Color version available online.

stituent concentrations, as it is highly plausible that $\mathrm{CR}$ is the element of the reproductive process most influenced by energy balance, and several milk constituent-based indicators are commonly used as proxy measure for herd-level energy status. As in previous work using a similar approach in data from UK herds (Madouasse et al., 2010), a large number of statistically

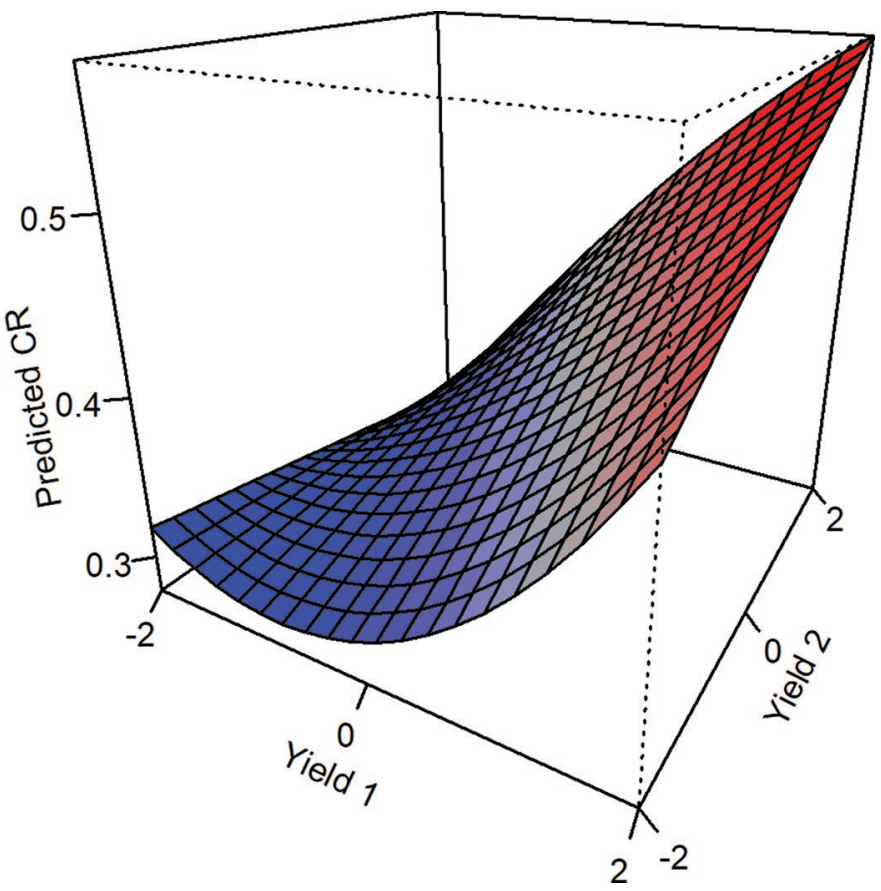

Figure 4. Regression surface illustrating the predicted relationship (from the model reported in Table 2) between conception risk (CR) and daily yield at first and second test day standardized such that 0 represents population mean and 1 represents mean plus $1 \mathrm{SD}$ compared with expected value given season and DIM at test day. Color version available online. significant associations were revealed (Table 2). Many of these relationships were not simple to interpret from model parameters because there were several interaction terms, both with early lactation variables and with stage of lactation. Graphical presentation of these results (Figure 2) using model predictions provides a more intuitive interpretation. Broadly, these findings agree with earlier work (Madouasse et al., 2010), with increased protein concentration at either of the first 2 test days and decreased butterfat concentration at the first test both generally associated with an increased probability of pregnancy. The association between early lactation lactose concentration and the outcome was more variable with DIM at insemination; this was especially marked for lactose at first test day.

For most of the relationships, the predicted CR varied relatively little over the range illustrated (2 SD below to $2 \mathrm{SD}$ above population mean). For example, an insemination at 50 DIM that was average in every respect would be expected to have a CR of just over $30 \%$ if lactose concentration at first test day was -2 (i.e., 2 SD below population mean); this would increase to just over $40 \%$ for a concentration of +2 (2 SD above the population mean). This range is likely to represent almost the full range of observed lactose concentrations (as $95 \%$ of values would be expected to lie within $2 \mathrm{SD}$ of the mean). Therefore, although this is one of the larger associations between milk constituent concentration and CR, lactose concentration would have to alter from close to the lowest observed level to close to the highest observed level to produce a meaningful change in $\mathrm{CR}$.

Taking all the milk constituent variables together, it appears that they collectively account for an extremely small proportion of observed variation in herd-year 
a) Full random effects

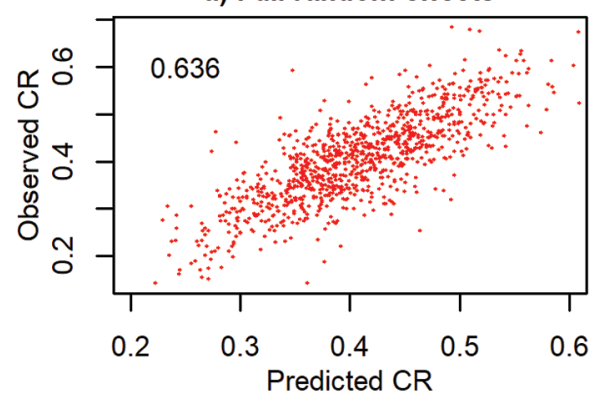

d) No milk constituent effects

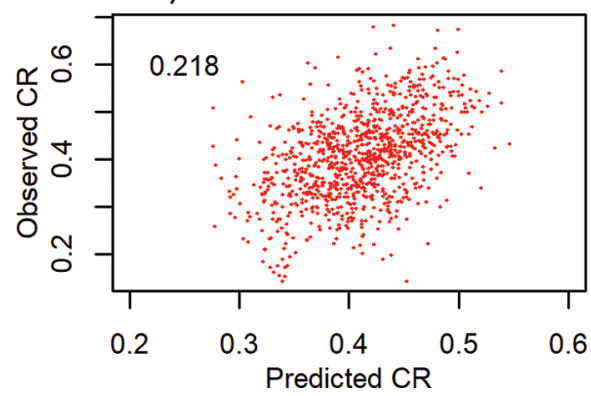

b) Herd random effect only

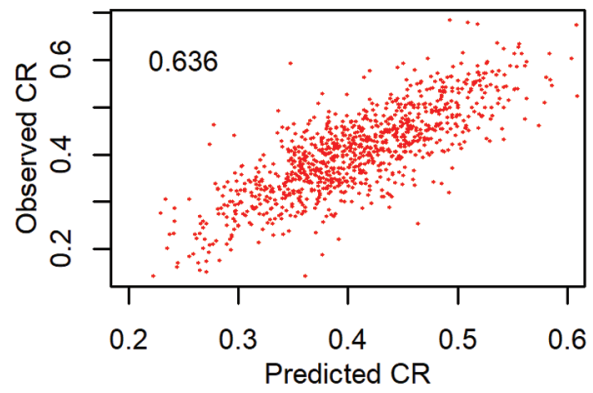

e) No milk const/yield effects

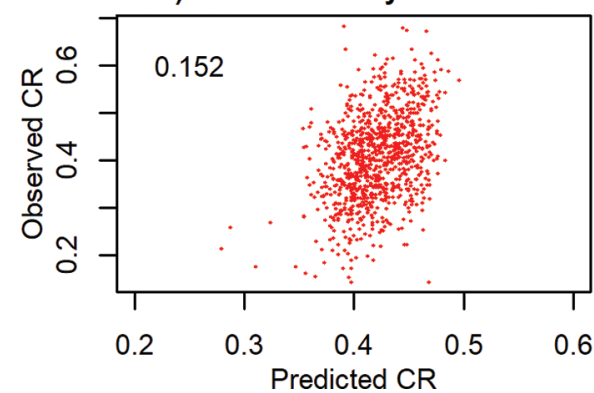

c) Fixed effects only

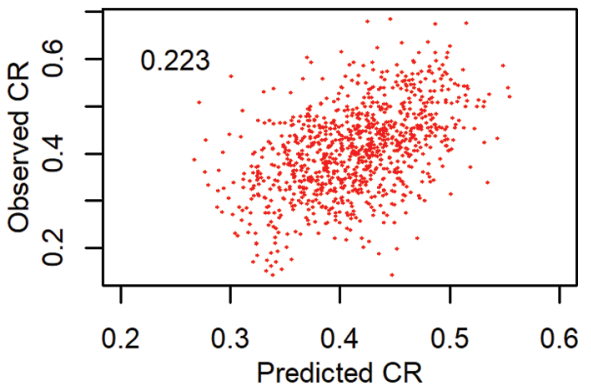

f) Proportion of variation explained

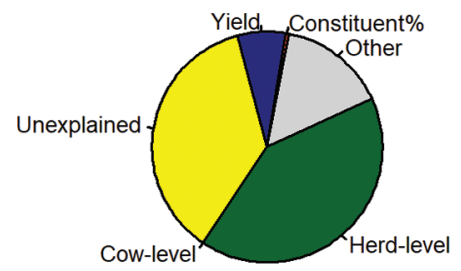

Figure 5. (a-e) Predicted versus observed herd-year conception risk (CR) generated using different elements of the model reported in Table 2. Plot titles show which elements of the model were used to create each set of predictions, and plot text shows Pearson $\mathrm{R}^{2}$ value for each correlation. (f) Proportion of variance in herd-year CR attributable to each model element. Yield includes all variables representing milk yield; constituent\% includes all variables based on milk constituent (const) concentrations; other includes all other fixed effects in the model. Herdlevel, cow-level, and unexplained show residual variation at each level of the model. Color version available online.

CR (Figure 5). There are several possible explanations for this - for example, that these parameters are not reliable predictors of early lactation energy balance in UK herds, or that early lactation energy balance has little effect on CR in early lactation. The latter seems highly unlikely because a considerable body of evidence demonstrates a strong link between energy balance and CR (Butler, 2003; Roche, 2006; Leroy et al., 2008b; Ospina et al., 2010). This study would therefore seem to suggest that milk constituent concentrations in early lactation do not predict energy balance at lactation level to a clinically useful extent in this sample of herds. This was despite the correction of these variables to account for variation introduced by DIM at time of test day and seasonality; Figure 1 (and the interactive online equivalents) shows that this variation is substantial and implies that use of uncorrected values is likely to be considerably less useful. For example, even within the typical sampling window of the first test day of lactation, fat:protein ratio (the most commonly used proxy measure) would be expected to vary from below 1.2 for a cow sampled at 5 DIM in early August to over 1.3 for a cow sampled at 23 DIM in February. However, it is also useful to remember that there are other reasons why these predictors would perhaps be expected to explain little of the herd-year variation in
CR - for example, the possibility that milk constituents vary mostly at cow level within herds, and the large number of other factors known to affect CR (in general, the more factors affect an outcome, the smaller the proportion of outcome variance explained by any individual factor).

The inclusion of 305-d adjusted lactation yield as well as daily yields at first and second test days of lactation allowed the effects of overall level of production and shape of the lactation curve through early lactation to be evaluated together. Broadly, higher levels of production (as measured by 305-d yield) were associated with lower CR, although for both first lactation and older cows very low yields were associated with a decreased CR. This apparently novel finding could plausibly be a result of a very low lactation yield acting as a marker of some unrecorded or unmeasurable disease event that had an effect on both production and fertility. For a given level of 305-d yield, CR was generally higher in lactations where daily yield increased steeply postcalving; this is in agreement with previous work in this field (Cook and Green, 2016), and measures based on yield at first test day or related to peak production have previously been suggested as markers of successful transition and early lactation health (Nordlund and Cook, 2004). Clearly, these findings do not imply a di- 
rectly causal relationship between 305-d yield and CR (e.g., because events occurring after conception may influence 305-d yield, and pregnancy itself is associated with a reduction in milk yield), and parameter estimates for the same model without the terms relating to 305-d yield are included in Supplemental Material (Supplemental Table S1 and Supplemental Figures S1 and S2; https://doi.org/10.3168/jds.2017-13962). However, it is expected that events occurring well after peak lactation are likely to have a small role in determining 305-d yield in most herds, and the effect of pregnancy on daily yield is relatively small and measurable only in mid to late gestation (Coulon et al., 2010), although other studies have found larger effects (van Amburgh et al., 1997). Taking this into consideration, inclusion of 305-d yield to represent overall level of production and provide better insight into other factors (e.g., parity) having accounted for this was felt to be useful.

In this study, inseminations in parity 1 (i.e., firstlactation animals) were associated with a lower CR compared with other lactation numbers once the other predictors in the model were accounted for. Several previous studies have reported higher CR in parity 1 (Gröhn and Rajala-Schultz, 2000; Cook and Green, 2016), including one using a smaller subset of the same data as was used in the current work (Hudson et al., 2012). Indeed, in a simple univariable analysis of the data set used in this study, parity 1 animals had a higher mean CR (44\%) than those in later parities (41, 40,39 , and $35 \%$ for parities $2,3,4$, and $>4$, respectively). This suggests that the relationship between CR and parity is confounded by other predictors accounted for in the model. Because many of the other variables in the model reported here were also included in other studies that found first-lactation animals to be more fertile than older individuals (e.g., Hudson et al., 2012), it is more likely that a novel element of the model reported here that was not included in previous work sheds new light on the relationship. Sequential removal of model terms revealed that the representation of 305$\mathrm{d}$ milk yield was key; when this was accounted for using separate polynomial terms for parity 1 and parity $>1$ (represented in Figure 3), a lower predicted CR for parity 1 was observed. This suggests that previous work may have found higher $\mathrm{CR}$ in first-lactation animals because these animals have lower milk yields, and lower milk yields have tended to be associated with increased fertility. Where yield is accounted for in a more complex way, it becomes clear that first-lactation animals tend to have a lower CR than would be expected given their level of production. Clear potential explanations for this finding exist: cows in the first lactation are usually among the least dominant animals in a group and so are more likely to have restricted access to any limited resources (e.g., where feed or water space is limited). It is also possible that this association is present only in early lactation: this study used inseminations at $<100$ DIM, whereas previous studies often cover different time periods.

Model predictions for CR across herd-years were used to explore how observed variation in $\mathrm{CR}$ is accounted for by the various elements of the model. Herd-years were used as the units in this case partly because these would represent the way in which such data are often assessed in the field and because herd-years were not directly included in the model as a random effect (as was, e.g., herd). Collectively, all of the fixed effect predictors in the model (see Table 2) explained just over $22 \%$ of the observed variation, with less than $1 \%$ accounted for by the predictors relating to early lactation milk constituent concentration and around $7 \%$ accounted for by predictors relating to milk yield (both overall level of production and shape of the early lactation curve). This reinforces the suggestion that early lactation milk constituents are not likely to be predictive of energy balance to a clinically useful extent.

The remaining variation in herd-year $\mathrm{CR}$ was split relatively evenly between the herd-level random effect and the bottom-level model residuals (i.e., the variation not explained by any elements of the model). This suggests that a large proportion of variation in $\mathrm{CR}$ is attributable to factors that are relatively consistent within herd over time but that were not measured in this data set or are not measurable. This could cover a wide range of factors, including environmental and feeding management, disease status, and inseminationrelated factors, and it is notable that the association between these unmeasured herd-level factors and herd-year CR is several times larger than that between $\mathrm{CR}$ and milk yield. The cow-level random effect term explained a negligible amount of variation in herd-year $\mathrm{CR}$, suggesting that unmeasured factors that are consistent within cow across inseminations and parities are unimportant as drivers of herd CR.

The use of predictions across herd-years also serves as an example of the value of carrying out further analysis to explain and contextualize the results of (especially logistic) regression analysis. Conventional presentation of model results as odds ratios alone (Table 2) would be difficult to interpret in this situation. In part, this is because of the complexity of the model; interaction terms and nonlinear representations of continuous predictors are inherently nonintuitive to interpret in a numerical format. Additionally, the intuitive tendency to interpret odds ratios as relative risks would also be a problem in this case. As the overall risk of pregnancy resulting from an insemination is relatively large, the odds of a successful insemination are substantially dif- 
ferent from the probability, and odds ratios will tend to exaggerate effect size (Davies et al., 1998). Several approaches can be useful to aid interpretation of such models. In addition to those reported here, population attributable risk (e.g., Peeler et al., 2000) and stochastic simulation modeling (e.g., Hudson et al., 2015) can be highly useful.

It is relevant to consider the potential for misclassification of the outcomes of inseminations with the methods used in this study. Subsequent calving date was the main determinant of insemination success; this was largely due to the source of the data. Use and recording of pregnancy diagnosis was according to each herd's usual practice and so was highly variable between herds. Clearly, this approach has potential for misclassification of outcome in both directions - for example, where 2 inseminations occur close together or where a cow aborts. Although the rules for determining the outcome in this study were designed to minimize such errors, some misclassification is still possible. However, the alternative approach of relying more heavily on pregnancy diagnosis records also has potential for misclassification and would have led to the exclusion of a large number of inseminations, plausibly in such a way that would introduce substantial bias (e.g., it is possible that a higher proportion of inseminations with no pregnancy diagnosis outcome are unsuccessful). Even if classification errors were evenly distributed, this would still have potential to influence the results of the study, generally by reducing the size of estimated coefficients and shifting variance from herd and cow level toward the bottom (unexplained) level. This is a feature inherent in such large-scale, retrospective studies.

Some features of the statistical modeling approach used in this study also merit discussion. As with all regression modeling, there were several somewhat subjective choices to be made during the model building process (e.g., interaction terms and nonlinear representation of continuous explanatory variables). In such cases, a balance needs to be struck between model complexity, informativeness, and the biological questions being explored. Although formal statistical methods balancing model fit against degree of complexity exist and were used to some extent here (e.g., deviance information criterion), the potential for overfitting also needs to be considered (Babyak, 2004). Use of internal cross-validation here helped to provide some evidence that overfitting had not occurred as well as provide some indication of potential out-of-sample predictiveness. The MCMC was used for final estimation of the reported model parameters. This has several advantages over conventional methods, including generally more robust parameter estimates for multilevel models (Browne and Draper, 2006) and a more intui- tive Bayesian interpretation of results than is the case for frequentist methods. For example, this approach produces a full posterior distribution for each model parameter, allowing probabilistic statements about results (e.g., "It is $95 \%$ probable that the true value for this parameter is between $\mathrm{X}$ and $\mathrm{Y}$ ") without relying on an understanding of the concept of long-run repetition. However, MCMC is substantially more computationally intensive than conventional methods. Evaluation of chain behavior should be a standard aspect of parameter estimation using MCMC. This study presents a robust approach to dealing with unexpected behavior of MCMC chains.

\section{CONCLUSIONS}

This study demonstrates that measures based on early lactation milk constituent concentrations are unlikely to predict herd-level CR to a clinically useful extent, even when corrected for potential nuisance factors such as season and DIM at sampling. A relatively sophisticated representation of milk yield (accounting for both overall level of yield and shape of lactation curve) was much more predictive of CR but still accounted for only around $7 \%$ of observed herd-year variation. After accounting for milk yield in this way, predicted CR was highest in parities 2 and 3 . Unmeasured effects that were consistent at herd level (represented by a herdlevel random effect) accounted for more than $40 \%$ of the variation, and further investigation into the herdlevel factors explaining this would be highly valuable.

\section{REFERENCES}

Archer, S. C., C. D. Hudson, and M. J. Green. 2015. Use of stochastic simulation to evaluate the reduction in methane emissions and improvement in reproductive efficiency from routine hormonal interventions in dairy herds. PLoS One 10:e0127846. https://doi.org/ 10.1371/journal.pone.0127846.

Babyak, M. A. 2004. What you see may not be what you get: A brief, nontechnical introduction to overfitting in regression-type models. Psychosom. Med. 66:411-421. https://doi.org/10.1097/01.psy .0000127692.23278.a9.

Blavy, P., M. Derks, O. Martin, J. K. Höglund, and N. C. Friggens. 2016. Overview of progesterone profiles in dairy cows. Theriogenology 86:1061-1071. https://doi.org/10.1016/j.theriogenology.2016 .03 .037 .

Browne, W. J. 2009. MCMC Estimation in MLwiN v2.20. Centre for Multilevel Modelling, University of Bristol, UK.

Browne, W. J., and D. Draper. 2006. A comparison of Bayesian and likelihood-based methods for fitting multilevel models. Bayesian Anal. 1:473-513.

Butler, W. R. 2001. Nutritional effects on resumption of ovarian cyclicity and conception rate in postpartum dairy cows. BSAP Occas. Pub. 26:133-146.

Butler, W. R. 2003. Energy balance relationships with follicular development, ovulation and fertility in postpartum dairy cows. Livest. Prod. Sci. 83:211-218. https://doi.org/10.1016/S0301 $-6226(03) 00112-\mathrm{X}$. 
Cook, J. G., and M. J. Green. 2016. Use of early lactation milk recording data to predict the calving to conception interval in dairy herds. J. Dairy Sci. 99:4699-4706. https://doi.org/10.3168/jds 2015-10264.

Coulon, J. B., L. Pérochon, and F. Lescourret. 2010. Modelling the effect of the stage of pregnancy on dairy cows' milk yield. Anim. Sci. 60:401-408. https://doi.org/10.1017/S1357729800013278.

Coulon, J. B., and B. Rémond. 1991. Variations in milk output and milk protein content in response to the level of energy supply to the dairy cow: A review. Livest. Prod. Sci. 29:31-47. https://doi .org/10.1016/0301-6226(91)90118-A.

Davies, H. T. O., I. K. Crombie, and M. Tavakoli. 1998. When can odds ratios mislead? BMJ 316:989-991. https://doi.org/10.1136/ bmj.316.7136.989.

de Vries, M. J., and R. F. Veerkamp. 2000. Energy balance of dairy cattle in relation to milk production variables and fertility. J. Dairy Sci. 83:62-69. https://doi.org/10.3168/jds.S0022-0302(00)74856-9.

Duffield, T. F., D. F. Kelton, K. E. Leslie, K. D. Lissemore, and J H. Lumsden. 1997. Use of test day milk fat and milk protein to detect subclinical ketosis in dairy cattle in Ontario. Can. Vet. J. 38:713-718.

Geishauser, T. D., K. E. Leslie, T. F. Duffield, and V. L. Edge. 1998 An evaluation of protein/fat ratio in first DHI test milk for prediction of subsequent displaced abomasum in dairy cows. Can. J. Vet. Res. 62:144-147.

Gröhn, Y. T., and P. J. Rajala-Schultz. 2000. Epidemiology of reproductive performance in dairy cows. Anim. Reprod. Sci. 60-61:605614. https://doi.org/10.1016/S0378-4320(00)00085-3.

Hanks, J., and M. Kossaibati. 2016. Key Performance Indicators for the UK National Dairy Herd. University of Reading, Reading, UK.

Heuer, C., Y. H. Schukken, and P. Dobbelaar. 1999. Postpartum body condition score and results from the first test day milk as predictors of disease, fertility, yield, and culling in commercial dairy herds. J. Dairy Sci. 82:295-304. https://doi.org/10.3168/jds.S0022 $-0302(99) 75236-7$.

Hudson, C., J. Breen, A. Bradley, and M. Green. 2010. Fertility in UK dairy herds: Preliminary findings of a large-scale study. Cattle Pract. 18:89-94.

Hudson, C. D., A. J. Bradley, J. E. Breen, and M. J. Green. 2012. Associations between udder health and reproductive performance in United Kingdom dairy cows. J. Dairy Sci. 95:3683-3697. https:// doi.org/10.3168/jds.2011-4629.

Hudson, C. D., A. J. Bradley, J. E. Breen, and M. J. Green. 2015. Dairy herd mastitis and reproduction: Using simulation to aid interpretation of results from discrete time survival analysis. Vet. J. 204:47-53. https://doi.org/10.1016/j.tvjl.2015.01.024.

Jorritsma, R., T. Wensing, T. A. M. Kruip, P. L. A. M. Vos, and J P. T. M. Noordhuizen. 2003. Metabolic changes in early lactation and impaired reproductive performance in dairy cows. Vet. Res. 34:11-26. https://doi.org/10.1051/vetres:2002054.

Leroy, J. L., T. Vanholder, A. T. M. Van Knegsel, I. Garcia-Ispierto, and P. E. J. Bols. 2008a. Nutrient prioritization in dairy cows early postpartum: Mismatch between metabolism and fertility? Reprod. Domest. Anim. 43:96-103.

Leroy, J. L., G. Opsomer, A. Van Soom, I. G. Goovaerts, and P. E. Bols. 2008b. Reduced fertility in high-yielding dairy cows: Are the oocyte and embryo in danger? Part I: The importance of negative energy balance and altered corpus luteum function to the reduction of oocyte and embryo quality in high-yielding dairy cows. Reprod. Domest. Anim. 43:612-622. https://doi.org/10.1111/j.1439 $-0531.2007 .00960 . x$.

Loeffler, S. H., M. J. de Vries, and Y. H. Schukken. 1999. The effects of time of disease occurrence, milk yield, and body condition on fertility in dairy cows. J. Dairy Sci. 82:2589-2604. https://doi.org/ 10.3168/jds.S0022-0302(99)75514-1.

Madouasse, A., J. N. Huxley, W. J. Browne, A. J. Bradley, I. L. Dryden, and M. J. Green. 2010. Use of individual cow milk record- ing data at the start of lactation to predict the calving to conception interval. J. Dairy Sci. 93:4677-4690. https://doi.org/10.3168/ jds.2010-3235.

McGuirk, B. J., I. Going, and A. R. Gilmour. 1998. The genetic evaluation of beef sires used for crossing with dairy cows in the UK-1. Sire breed and non-genetic effects on calving survey traits. Anim. Sci. 66:35-45. https://doi.org/10.1017/S135772980000881X.

McGuirk, B. J., I. Going, and A. R. Gilmour. 1999. The genetic evaluation of UK Holstein Friesian sires for calving ease and related traits. Anim. Sci. 68:413-422. https://doi.org/10.1017/ S1357729800050414.

Morton, J. 2011. InCalf Fertility Data Project 2011. Dairy Australia, Southbank, VIC, Australia.

Nordlund, K. V., and N. B. Cook. 2004. Using herd records to monitor transition cow survival, productivity, and health. Vet. Clin. North Am. Food Anim. Pract. 20:627-649. https://doi.org/10.1016/j .cvfa.2004.06.012.

Norman, H. D., J. R. Wright, S. M. Hubbard, R. H. Miller, and J. L. Hutchison. 2009. Reproductive status of Holstein and Jersey cows in the United States. J. Dairy Sci. 92:3517-3528. https://doi.org/ $10.3168 /$ jds. $2008-1768$

Ospina, P. A., D. V. Nydam, T. Stokol, and T. R. Overton. 2010. Associations of elevated nonesterified fatty acids and $\beta$-hydroxybutyrate concentrations with early lactation reproductive performance and milk production in transition dairy cattle in the northeastern United States. J. Dairy Sci. 93:1596-1603. https://doi.org/10.3168/jds .2009-2852.

Peeler, E. J., M. J. Green, J. L. Fitzpatrick, K. L. Morgan, and L. E. Green. 2000. Risk factors associated with clinical mastitis in low somatic cell count British dairy herds. J. Dairy Sci. 83:2464-2472. https://doi.org/10.3168/jds.S0022-0302(00)75138-1.

Podpečan, O., J. Mrkun, and P. Zrimšek. 2008. Diagnostic evaluation of fat to protein ratio in prolonged calving to conception interval using receiver operating characteristic analyses. Reprod. Domest. Anim. 43:249-254. https://doi.org/10.1111/j.1439-0531 2007.00895.x.

R Core Development Team. 2010. R: A Language and Environment for Statistical Computing. R Foundation for Statistical Computing, Vienna, Austria.

Rasbash, J., C. Charlton, W. J. Browne, M. Healy, and B. Cameron. 2010. MLwiN Version 2.2. Centre for Multilevel Modelling, University of Bristol, UK.

Remnant, J. G., M. J. Green, J. N. Huxley, and C. D. Hudson. 2015. Variation in the interservice intervals of dairy cows in the United Kingdom. J. Dairy Sci. 98:889-897. https://doi.org/10.3168/jds .2014-8366.

Roche, J. R. 2006. The effect of nutritional management of the dairy cow on reproductive efficiency. Anim. Reprod. Sci. 96:282-296. https://doi.org/10.1016/j.anireprosci.2006.08.007.

Spiegelhalter, D. J., N. G. Best, B. R. Carlin, and A. van der Linde. 2002. Bayesian measures of model complexity and fit. J. R. Stat. Soc. B 64:583-616.

van Amburgh, M. E., D. M. Galton, D. E. Bauman, and R. W. Everett. 1997. Management and economics of extended calving intervals with use of bovine somatotropin. Livest. Prod. Sci. 50:15-28. https://doi.org/10/1016/S0301-6226(07)00069-9.

Villa-Godoy, A., T. L. Hughes, R. S. Emery, L. T. Chapin, and R. L. Fogwell. 1988. Association between energy balance and luteal function in lactating dairy cows. J. Dairy Sci. 71:1063-1072. https:// doi.org/10.3168/jds.S0022-0302(88)79653-8.

Wathes, D. C., M. Fenwick, Z. Cheng, N. Bourne, S. Llewellyn, D. G. Morris, D. Kenny, J. Murphy, and R. Fitzpatrick. 2007. Influence of negative energy balance on cyclicity and fertility in the high producing dairy cow. Theriogenology 68(Suppl. 1):S232-S241. https://doi.org/10.1016/j.theriogenology.2007.04.006. 